Open Access

\title{
Structural and spectral investigations of the recently synthesized chalcone $(E)$-3-mesityl- 1-(naphthalen-2-yl) prop-2-en-1-one, a potential chemotherapeutic agent
}

\author{
Assem Barakat ${ }^{1,2^{*}}$, Abdullah Mohammed Al-Majid', Saied M Soliman², Yahia Nasser Mabkhot ${ }^{1}$, M Ali $^{1}$,
} Hazem A Ghabbour ${ }^{3}$, Hoong-Kun Fun ${ }^{3,4}$ and Abdul Wadood ${ }^{5}$

\begin{abstract}
Background: Chalcones (1,3-diaryl-2-propen-1-ones, represent an important subgroup of the polyphenolic family, which have shown a wide spectrum of medical and industrial application. Due to their redundancy in plants and ease of preparation, this category of molecules has inspired considerable attention for potential therapeutic uses. They are also effective in vivo as anti-tumor promoting, cell proliferating inhibitors and chemo preventing agents.

Results: Synthesis and molecular structure investigation of (E)-3-mesityl-1-(naphthalen-2-yl) prop-2-en-1-one (3) is reported. The structure of the title compound 3 is confirmed by X-ray crystallography. The optimized molecular structure of the studied compound is calculated using DFT B3LYP/6-311G $(\mathrm{d}, \mathrm{p})$ method. The calculated geometric parameters are in good agreement with the experimental data obtained from our reported $X$-ay structure. The calculated IR fundamental bands were assigned and compared with the experimental data. The electronic spectra of the studied compound have been calculated using the time dependant density functional theory (TD-DFT). The longest wavelength band is due to $\mathrm{H} \rightarrow \mathrm{L}$ (79 \%) electronic transition which belongs to $\pi-\pi^{*}$ excitation. The ${ }^{1} \mathrm{H}$ - and ${ }^{13} \mathrm{C}$-NMR chemical shifts were calculated using gauge independent atomic orbitals (GIAO) method, which showed good correlations with the experimental data $\left(R^{2}=0.9911-0.9965\right)$. The natural bond orbital (NBO) calculations were performed to predict the natural atomic charges at different atomic sites. The molecular electrostatic potential (MEP) was used to visualize the charge distribution on the molecule. Molecular docking results suggest that the compound might exhibit inhibitory activity against GPb and may act as potential anti-diabetic compound.

Conclusions: (E)-3-Mesityl-1-(naphthalen-2-yl) prop-2-en-1-one single crystal is grown and characterized by single crystal X-ray diffraction, FT-IR, UV-Vis, DFT and optimized geometrical parameters are close to the experimental bond lengths and angles. Molecular stability was successfully analyzed using NBO and electron delocalization is confirmed by MEP. Prediction of Activity Spectra Analysis of the title compound, predicts anti-diabetic activity with probability to have an active value of 0.348 .
\end{abstract}

Keywords: Aldol product, Chalcone, X-Ray, DFT compution, PAAS

\footnotetext{
* Correspondence: ambarakat@ksu.edu.sa

'Department of Chemistry, College of Science, King Saud University,

P.O. Box 2455, 11451 Riyadh, Saudi Arabia

${ }^{2}$ Department of Chemistry, Faculty of Science, Alexandria University,

P.O. Box 426, 21321 Alexandria, Ibrahimia, Egypt

Full list of author information is available at the end of the article
} 


\section{Background}

Chalcones, constitute one of the major classes of flavonoids and isoflavonoids, with widespread distribution in fruits, vegetables, soy and tea.

Chalcones (1,3-diaryl-2-propen-1-ones), have a framework, where two aromatic rings are linked by a three carbon $\alpha, \beta$ - unsaturated carbonyl system. Contemporary studies report a generous variation of significant pharmacological activities of chalcones including anti-fungal [1-3], anti-bacterial [4], anti-tumor [5-8], and antiinflammatory activities [9]. These activities are largely attributed to the $\alpha, \beta$ - unsaturated ketone moiety. However, the interest and development of synthetic chalcone derivatives to achieve different pharmacological activities has increased in recent years in order to establish more advanced structure-activity relationships and to generate novel compounds with diverse substituent patterns.

Chalcones is a versatile pharmacophore as compounds bearing this structural synthon possess a broad spectrum of biological activities such as anticancer potencies towards human leukemia HL-60, mouse lymphoma P388 cells [10], HeLa cell lines [11] as well as possessing antileishmanial activity [12]. In addition, several chalcones and aurones also possess an appealing pharmacological profile combining high antioxidant and lipid peroxidation activity with potent soybean LOX inhibition [13]. Julio et al., have prepared a series of highly functionalized chalcones. High levels of antiparasitic inhibitory activity against Giardia lamblia have been found within the series [14]. Anindra et al., have designed and studied the anticancer activity of a novel series of substituted chalcones. The preliminary anticancer activity of the tested compounds showed potent inhibitory activity towards human breast cancer cell lines [15].

The Claisen-Schmidt reaction (cross-Aldol reaction) is a condensation reaction of appropriate acetophenones derivatives with suitable aromatic aldehyde and has been playing important roles in synthetic organic chemistry [16]. Thus, the synthesis of chalcones has attracted the attention of synthetic organic/medicinal chemists. Diabetes mellitus is a principal cause of mortality and morbidity in human populations. It is a syndrome characterized by polydipsia, polyuria and hyperglycemia due to either a deficiency in the production or secretion of insulin, diminished tissue response to the actions of insulin, or both. Additionally, it causes complications to the kidneys, eyes, and nerves. It is also associated with an increased incidence of cardiovascular disease [17].

Organic molecular systems having conjugated $\pi$-systems, such as naphthalenes [18], are of great interest as potential materials for the applications related to the nonlinear optical (NLO) properties. These organic compounds are currently attracting considerable attention because of their potential applications in the optoelectronic devices of telecommunications, information storage, optical switching, signal processing [19-23] and terahertz $(\mathrm{THz})$ wave generation [24]. The substituent attached to the conjugated $\pi$-system plays a vital role in terms of NLO activity. By increasing the donor-acceptor capability of the substitutions attached to the $\pi$-conjugated system, nonlinearity can be increased. The large value of the hyperpolarizability, $\beta$, which is the measure of the nonlinear optical activity of the molecular system, is associated with intramolecular charge transfer resulting from an electron cloud movement through a $\pi$-conjugated framework from electron donor to electron acceptor groups. The design of new systems with a high charge transfer is a key part of this, because intramolecular charge transfer between donor and acceptor will lead to a very large value for $\beta$. From this point of view, the theoretical prediction of accurate electro-optical properties for this kind of system is a very important step towards the rational design of novel nonlinear optical materials. The study of such effects involves the initial determination of static polarizabilities and hyperpolarizabilities in the gas phase.

In view of the above mentioned facts and in continuation of our interest, the structure of (E)-3-mesityl-1(naphthalen-2-yl) prop-2-en-1-one 3 was unambiguously elucidated by single-crystal X-ray diffraction technique. Additionally, the DFT/B3LYP calculations have been performed to study the molecular structure characteristics of the studied compound. The electronic and spectroscopic (FTIR, UV-vis and NMR) properties of the studied compound have been predicted using the same level of theory. NBO calculations were used to calculate the natural charges at the different atomic sites. Also, molecular docking simulations for the title compound were carried out.

\section{Results and discussion Chemistry}

The key chalcone $\mathbf{3}$ was synthesized by a base-catalyzed Claisen Schmidt reaction between equimolar amount of
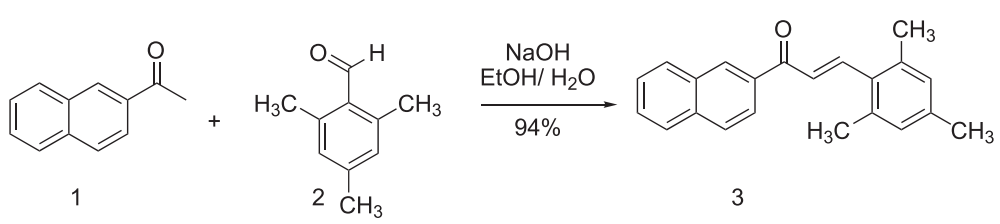

Scheme 1 Preparation of the title compound 3 


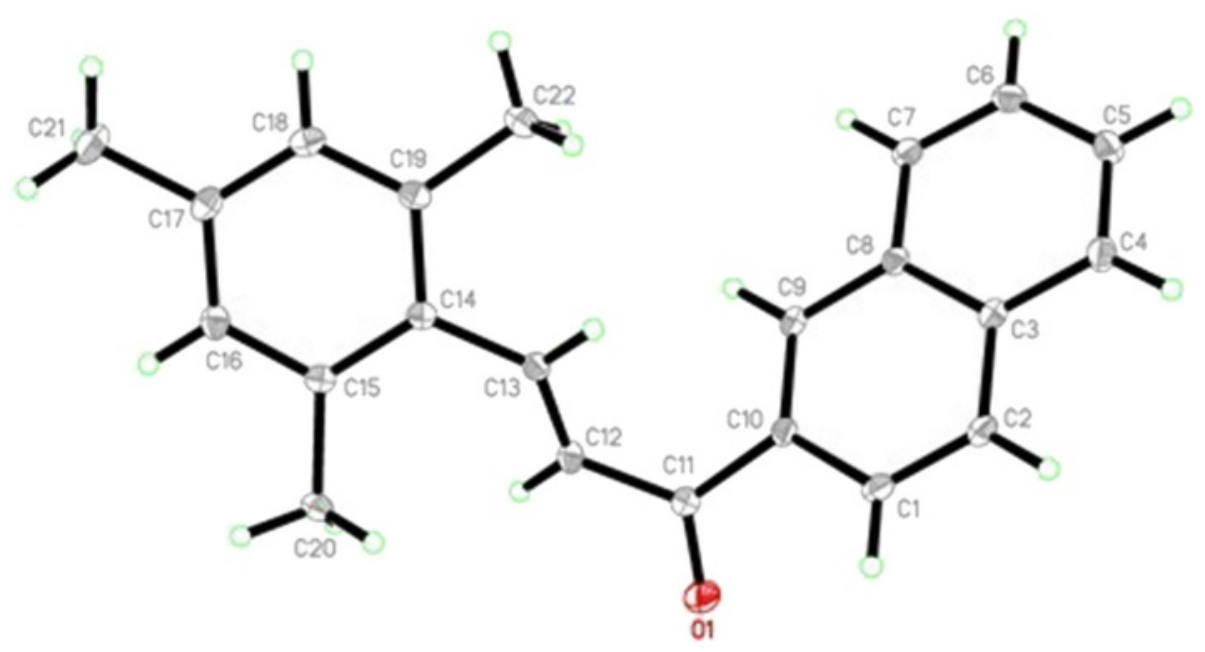

Fig. 1 The ORTEP diagram of the final X-ray model of 3 with displacement ellipsoids drawn at $30 \%$ probability level

2-acetyl naphthalene and 2,4,6-trimethylbenzaldehyde in excellent yield (94\%) as illustrated in Scheme 1 [25]. Mechanistically, the reaction involves formation of a carbanion from the 2-acetyl naphthalene in the presence of base, followed by nucleophilic attack by the carbanion on the carbonyl carbon of the aldehyde and subsequent loss of water to give the chalcone.

The chemical structure of compound $\mathbf{3}$ was elucidated by its spectroscopic data including GCMS, ${ }^{1} \mathrm{H},{ }^{13} \mathrm{C}$ NMR, IR and single crystal X-ray structure.

\section{Molecular structure of compound 3}

The asymmetric unit contains one molecule. The crystal structure of compound $\mathbf{3}$ is composed of naphthalene $(\mathrm{C} 1-\mathrm{C} 10)$ and mesitylene $(\mathrm{C} 14-\mathrm{C} 19)$ rings linked through prop-1-en-2-one (Fig. 1). The dihedral angle between the two ring systems is 36.24 (2) ${ }^{\circ}$ and the bond length between C12 and C13 is 1.342 (2) which indicates its double bond nature. The crystal packing shows that the molecules are arranged in rows along the $a$-axis and these rows are stacked by $\mathrm{C}-\mathrm{H} \cdots \pi$ interactions (see Tables 1 and 2) along the $c$-axis (Fig. 2). No significant hydrogen bonds were found. Additional file 1: Table S1. Geometric parameters $\left(\AA,^{\circ}\right)$ compound 3 .

\section{Computational details}

All the quantum chemical calculations of the studied compound were performed by applying DFT method with the B3LYP functional and 6-311G (d,p) basis set using Gaussian 03 software [26]. The input file was taken from the CIF obtained from our reported X-ray single crystal measurement. The geometry was optimized by minimizing the energies with respect to all the geometrical parameters without imposing any molecular symmetry constraints. GaussView4.1 [27] and Chemcraft
Table 1 The crystal and experimental data of compound 3

\begin{tabular}{|c|c|}
\hline \multicolumn{2}{|l|}{ Crystal data } \\
\hline Chemical formula & $\mathrm{C}_{22} \mathrm{H}_{20} \mathrm{O}$ \\
\hline$M_{\mathrm{r}}$ & 300.38 \\
\hline Crystal system, space group & Orthorhombic, $P_{c a 2_{1}}$ \\
\hline Temperature (K) & 100 \\
\hline$a, b, c(\AA)$ & 27.3605 (9), $7.8271(3), 7.4710(2)$ \\
\hline$V\left(\AA^{3}\right)$ & $1599.94(9)$ \\
\hline Z & 4 \\
\hline Radiation type & Mo Ka \\
\hline$\mu(m m-1)$ & 0.07 \\
\hline Crystal size (mm) & $0.67 \times 0.27 \times 0.16$ \\
\hline \multicolumn{2}{|l|}{ Data collection } \\
\hline Diffractometer & $\begin{array}{l}\text { BrukerAPEX-II D8 Venture } \\
\text { diffractometer }\end{array}$ \\
\hline Absorption correction & Multi-scan \\
\hline \multicolumn{2}{|l|}{ SADABS V2012/1 (Bruker AXS Inc.) } \\
\hline Tmin, Tmax & $0.94,0.99$ \\
\hline $\begin{array}{l}\text { No. of measured, independent and } \\
\text { observed }[1>2 \sigma(1)] \text { reflections }\end{array}$ & $38877,4902,4472$ \\
\hline Rint & 0.042 \\
\hline \multicolumn{2}{|l|}{ Refinement } \\
\hline $\mathrm{R}[\mathrm{F} 2>2 \sigma(\mathrm{F} 2)], \mathrm{wR}(\mathrm{F} 2), \mathrm{S}$ & $0.041,0.107,1.05$ \\
\hline No. of reflections & 4902 \\
\hline No. of parameters & 211 \\
\hline No. of restraints & 1 \\
\hline $\mathrm{H}$-atom treatment & $\mathrm{H}$-atom parameters constrained \\
\hline$\Delta \rho_{\max ,} \Delta \rho_{\min }\left(\mathrm{e} \AA^{-3}\right)$ & $0.39,-0.19$ \\
\hline
\end{tabular}


Table 2 Hydrogen-bond geometry $\left(\AA^{\circ},{ }^{\circ}\right)$ of 3

\begin{tabular}{lllll}
\hline $\mathrm{D}-\mathrm{H} \cdots \mathrm{A}$ & $\mathrm{D}-\mathrm{H}$ & $\mathrm{H} \cdots \mathrm{A}$ & $\mathrm{D} \cdots \mathrm{A}$ & $\mathrm{D}-\mathrm{H} \cdots \mathrm{A}$ \\
\hline $\mathrm{C} 2-\mathrm{H} 2 \mathrm{~A} \cdots \mathrm{Cg} 2^{\mathbf{i}}$ & 0.9300 & 2.92 & $3.7101(17)$ & 143 \\
$\mathrm{C} 4-\mathrm{H} 4 \mathrm{~A} \cdots \mathrm{Cg} 1^{\mathbf{i}}$ & 0.9300 & 2.59 & $3.3807(17)$ & 143 \\
$\mathrm{C} 16-\mathrm{H} 16 \mathrm{~A} \cdots \mathrm{Cg} 1^{\mathrm{ii}}$ & 0.9300 & 2.98 & $3.5506(17)$ & 121 \\
$\mathrm{C} 21-\mathrm{H} 21 \mathrm{C} \cdots \mathrm{Cg} 2^{\mathrm{ii}}$ & 0.9600 & 2.84 & $3.624(2)$ & 140 \\
$\mathrm{C} 22-\mathrm{H} 22 \mathrm{~B} \cdots \mathrm{Cg} 3^{\mathrm{iii}}$ & 0.9600 & 2.83 & $3.754(2)$ & 162
\end{tabular}

Symmetry code: (i) $1-X, 1-Y,-1 / 2+Z$. (ii) $1 / 2-X, Y, 1 / 2+Z$. (iii) $1 / 2-X, Y,-1 / 2+Z$ $\mathrm{Cg} 1$ is the centroid of the $\mathrm{C} 1-\mathrm{C} 3 / \mathrm{C} 8-\mathrm{C} 10$ ring, $\mathrm{Cg} 2$ is the centroid of the $\mathrm{C} 3-\mathrm{C} 8$ ring and $\mathrm{Cg} 3$ is the centroid of the $\mathrm{C} 14-\mathrm{C} 19$ ring. No significant hydrogen bonds were found

[28] programs have been used to draw the structure of the optimized geometry and to visualize the MEP, HOMO and LUMO pictures. Frequency calculations at the optimized geometry were done to confirm the optimized structure to be at an energy minimum. The true energy minimum at the optimized geometry of the studied compound was confirmed by absence of any imaginary frequency modes. Vibrational mode assignments were made by visual inspection of the modes animated by using GaussView program [27]. The electronic spectra of the studied compound were calculated by the TD-DFT method. The gauge including atomic orbital (GIAO) method was used for the NMR calculations. The ${ }^{1} \mathrm{H}$ and the ${ }^{13} \mathrm{C}$ isotropic shielding tensors referenced to the TMS calculations were carried out at the same level of theory. The natural atomic charges were calculated using NBO method as implemented in the Gaussian 03 package [29] at the DFT/B3LYP level.

\section{Optimized molecular geometry}

The optimized bond lengths and bond angles obtained for the studied compound using the B3LYP method with 6-311G (d,p) basis set are given in Table 3; while the atom numbering of the optimized structure is given in Fig. 3. The studied compound possesses $C_{1}$ point group. The optimized geometric parameters of the studied compound are compared with those obtained from the crystallographic information file (CIF) as shown in Fig. 4. Some of these geometric parameters are overestimated while the others are underestimated. The maximum deviations of the calculated bond length and bond angle values from the experimental data are $0.005-0.007$ $\AA$ (O1-Cl9 and $\mathrm{C} 19-\mathrm{C} 20)$ and $1.058^{\circ}(\mathrm{O} 1-\mathrm{C} 19-\mathrm{C} 20)$ respectively. These little deviations are attributed to the phase difference between the calculated and the experimental data. The root mean square deviation (RMSD), the percentage relative error and the correlation coefficient (R2) values between the experimental and calculated bond distances are found to be $0.003 \AA$, $0.492 \%$ and 0.9989 , respectively. Generally, the bond lengths and bond angles are predicted very well.

The calculations predicted the $\mathrm{O} 1 \ldots \mathrm{H} 3$ and $\mathrm{O} 1 \ldots \mathrm{H} 21$ intramolecular distances are $2.532 \AA$ (exp. $2.641 \AA$ ) and $2.519 \AA$ (exp. $2.561 \AA$ ) respectively. These results indicate the presence of weak nonconventional $\mathrm{C}-\mathrm{H}$...O intramolecular $\mathrm{H}$-bonding interactions. Moreover, the $\mathrm{C}-\mathrm{C}-\mathrm{C}-\mathrm{C}$ dihedral angles of the aromatic rings did not exceed $2.054^{\circ}$ indicating, commonly, the planar structure of these rings. On other hand, the C16-C18-C19-O1

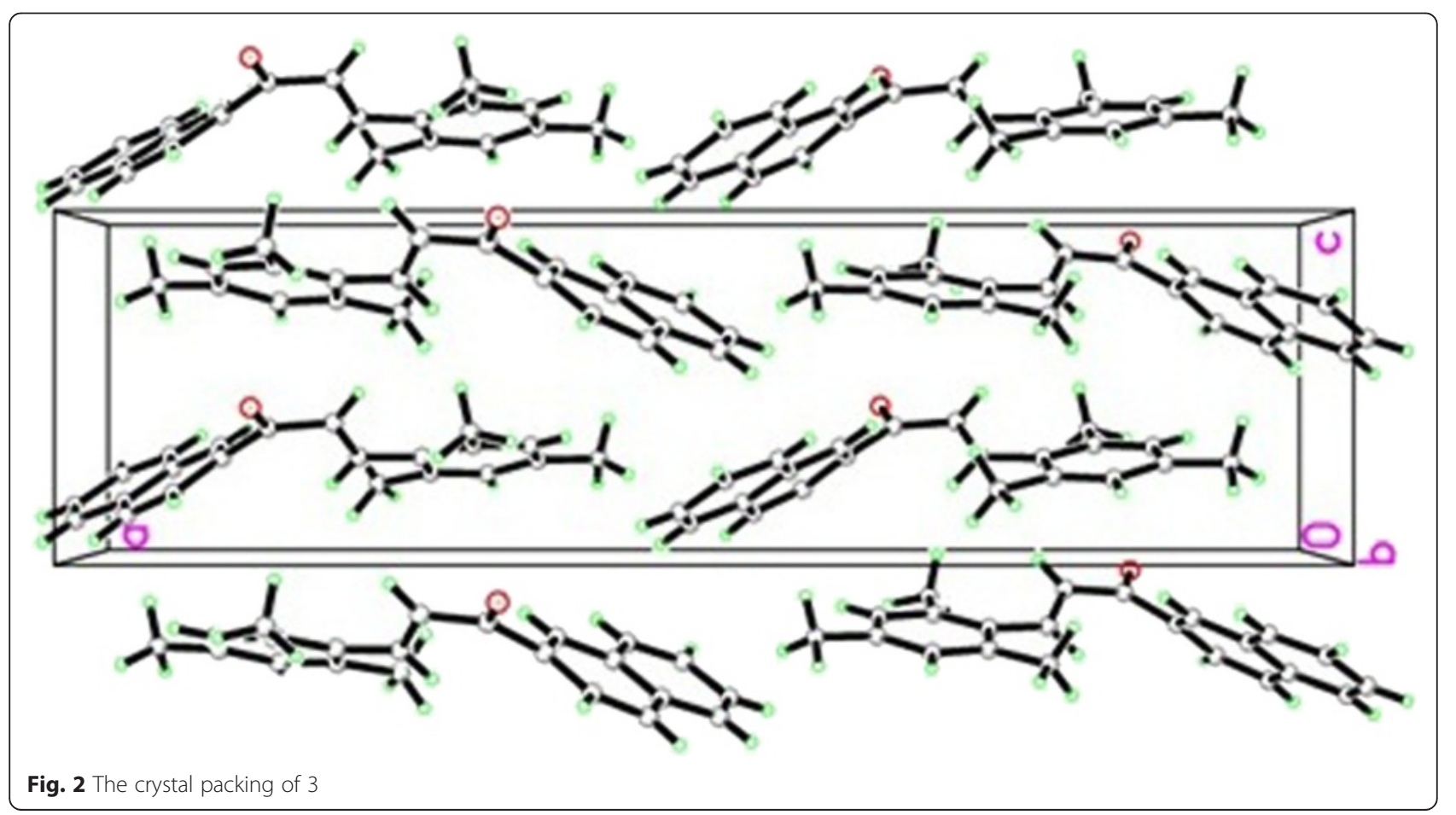


Table 3 The calculated and experimental geometric parameters of the studied compound 3 using B3LYP/6-311G (d,p) method

\begin{tabular}{llllll}
\hline Parameter & Calc. & Exp & Parameter & Calc. & Exp \\
\hline R (1-19) & 1.223 & 1.228 & A (4-6-7) & 122.5 & 121.7 \\
R (2-4) & 1.369 & 1.366 & A (4-6-15) & 118.6 & 119.2 \\
R (2-18) & 1.422 & 1.420 & A (7-6-15) & 118.9 & 119.1 \\
R (4-6) & 1.421 & 1.425 & A (6-7-8) & 118.8 & 119.7 \\
R (6-7) & 1.418 & 1.418 & A (6-7-9) & 120.8 & 120.7 \\
R (6-15) & 1.430 & 1.423 & A (6-15-13) & 119.0 & 119.0 \\
R (7-9) & 1.375 & 1.371 & A (6-15-16) & 119.0 & 118.9 \\
R (9-11) & 1.414 & 1.413 & A (7-9-11) & 120.4 & 120.3 \\
R (11-13) & 1.374 & 1.374 & A (9-11-13) & 120.2 & 120.4 \\
R (13-15) & 1.419 & 1.421 & A (11-13-15) & 120.8 & 120.5 \\
R (15-16) & 1.418 & 1.420 & A (13-15-16) & 122.1 & 122.1 \\
R (16-18) & 1.380 & 1.378 & A (15-16-18) & 121.3 & 120.7 \\
R (18-19) & 1.502 & 1.499 & A (16-18-19) & 122.9 & 122.6 \\
R (19-20) & 1.484 & 1.477 & A (18-19-20) & 121.7 & 121.0 \\
R (20-22) & 1.345 & 1.342 & A (20-22-24) & 128.3 & 128.4 \\
R (22-24) & 1.472 & 1.469 & A (22-24-25) & 123.5 & 123.6 \\
R (24-25) & 1.416 & 1.415 & A (22-24-31) & 117.5 & 117.1 \\
R (24-31) & 1.420 & 1.416 & A (25-24-31) & 118.9 & 119.3 \\
R (25-26) & 1.398 & 1.398 & A (24-25-26) & 119.0 & 118.9 \\
R (25-32) & 1.512 & 1.510 & A (24-25-32) & 123.6 & 123.8 \\
R (26-28) & 1.392 & 1.391 & A (24-31-29) & 119.8 & 119.6 \\
R (28-29) & 1.396 & 1.392 & A (24-31-40) & 121.5 & 121.7 \\
R (28-36) & 1.508 & 1.508 & A (26-25-32) & 117.4 & 117.2 \\
R (29-31) & 1.391 & 1.393 & A (25-26-28) & 122.6 & 122.0 \\
R (31-40) & 1.512 & 1.513 & A (25-32-33) & 110.0 & 109.5 \\
A (1-19-20) & 118.8 & 119.8 & A (26-28-29) & 117.8 & 118.5 \\
A (4-2-18) & 120.7 & 120.7 & A (26-28-36) & 121.4 & 120.6 \\
A (2-4-5) & 120.2 & 119.8 & A (29-28-36) & 120.9 & 120.9 \\
A (2-4-6) & 121.0 & 120.5 & A (28-29-31) & 121.9 & 121.5 \\
A (2-18-16) & 119.3 & 120.0 & A (30-29-31) & 118.9 & 119.2 \\
A (2-18-19) & 117.6 & 117.2 & A (29-31-40) & 118.7 & 118.5 \\
\hline & & & & & \\
\hline
\end{tabular}

$\left(33.4^{\circ}\right), \mathrm{C} 2-\mathrm{C} 18-\mathrm{C} 19-\mathrm{O} 1 \quad\left(28.2^{\circ}\right), \mathrm{C} 31-\mathrm{C} 24-\mathrm{C} 22-\mathrm{C} 20$ $\left(33.6^{\circ}\right)$ and $\mathrm{C} 25-\mathrm{C} 24-\mathrm{C} 22-\mathrm{C} 20\left(35.7^{\circ}\right)$ dihedral angles indicated that the $\mathrm{C} 19=\mathrm{O} 1$ and the $\mathrm{C} 20=\mathrm{C} 22$ are not coplanar with the naphthalene and benzene rings, respectively.

\section{Natural atomic charge}

Charge distribution has a vital role in the application of quantum chemical calculations to molecular system because atomic charges affect many properties such as dipole moment, molecular polarizability, electronic structure and acidity-basicity behaviour of compound [30]. These electronic properties have strong relations to the biological activity of compound. In this regards, the natural atomic charges (NAC) were calculated using NBO method at the DFT B3LYP/6-311G (d,p) level of theory and the results are given in Table 4. The $\mathrm{O} 1$ and methyl carbon (C32, C36 and C40) atoms have the highest negative natural charge values while the carbonyl carbon $(\mathrm{C} 19)$ is the most electropositive atom in the molecule. The reason is the high electronegativity of the $\mathrm{O}$-atom attached to it. All the $\mathrm{H}$-atoms are electropositive. The calculated natural atomic charge values at the $\mathrm{H}$-sites are in the range 0.1961-0.2212. Of the $\mathrm{C}\left(\mathrm{sp}^{2}\right)-\mathrm{H}$ protons, the $\mathrm{H} 3$ and $\mathrm{H} 21$ have the highest NAC values probably due to the $\mathrm{C}-\mathrm{H}$...O interactions.

Molecular electrostatic potential maps are very useful three dimensional diagrams which are used to visualize the charge distributions and charge related properties of molecules. Also, MEP picture has been used to predict the reactive sites for electrophilic and nucleophilic attack, and in studies of biological recognition and hydrogen bonding interactions $[31,32]$. The MEP of the studied compound calculated using B3LYP method with 6-311G (d,p) basis set is shown in Fig. 5. It can be seen from the MEP figure; negative regions (red) are mainly localized over the carbonyl oxygen atom while the positive regions (blue) are distributed over the $\mathrm{H}$-atoms.

\section{Frontier molecular orbitals}

The electron densities of the frontier molecular orbitals (FMOs) were used for predicting the most reactive position in $\pi$-electron systems and to explaine several types of reactions in conjugated system [33]. The properties of these FMOs like energy are very useful for physicists and chemists. The energy values of the lowest unoccupied molecular orbital ( $\left.\mathrm{E}_{\mathrm{LUMO}}\right)$ and the highest occupied molecular orbital $\left(\mathrm{E}_{\mathrm{HOMO}}\right)$ and their energy gap $(\Delta \mathrm{E})$ reflect the chemical reactivity of the molecule. Recently the energy gap between HOMO and LUMO has been used to prove the bioactivity from intramolecular charge transfer (ICT) [34, 35]. The $\mathrm{E}_{\mathrm{HOMO}}, \mathrm{E}_{\mathrm{LuMO}}$ and $\Delta \mathrm{E}$ values for the studied compound were calculated by B3LYP/6-311G (d,p) method. The HOMO and LUMO pictures are shown in Fig. 6. It is found that the HOMO and LUMO levels are distributed mainly over the ring ( $\pi$-system). The $\mathrm{E}_{\mathrm{HOMO}}$ and $\mathrm{E}_{\mathrm{LUMO}}$ are calculated to be $6.2543 \mathrm{eV}$ and $-2.0458 \mathrm{eV}$ respectively. The HOMOLUMO energy gap $(\Delta \mathrm{E})$ represents the lowest energy electronic transition which mainly belongs to $\pi-\pi^{*}$ excitation $(4.2085 \mathrm{eV})$.

The more accurate electronic transitions were calculated using the time-dependant density functional theory (TD-DFT). The twenty spin allowed singlet-singlet electronic transitions using the TD-DFT method are given in Additional file 1: Table S2. The experimental and calculated electronic spectra are shown in Fig. 7. The studied 


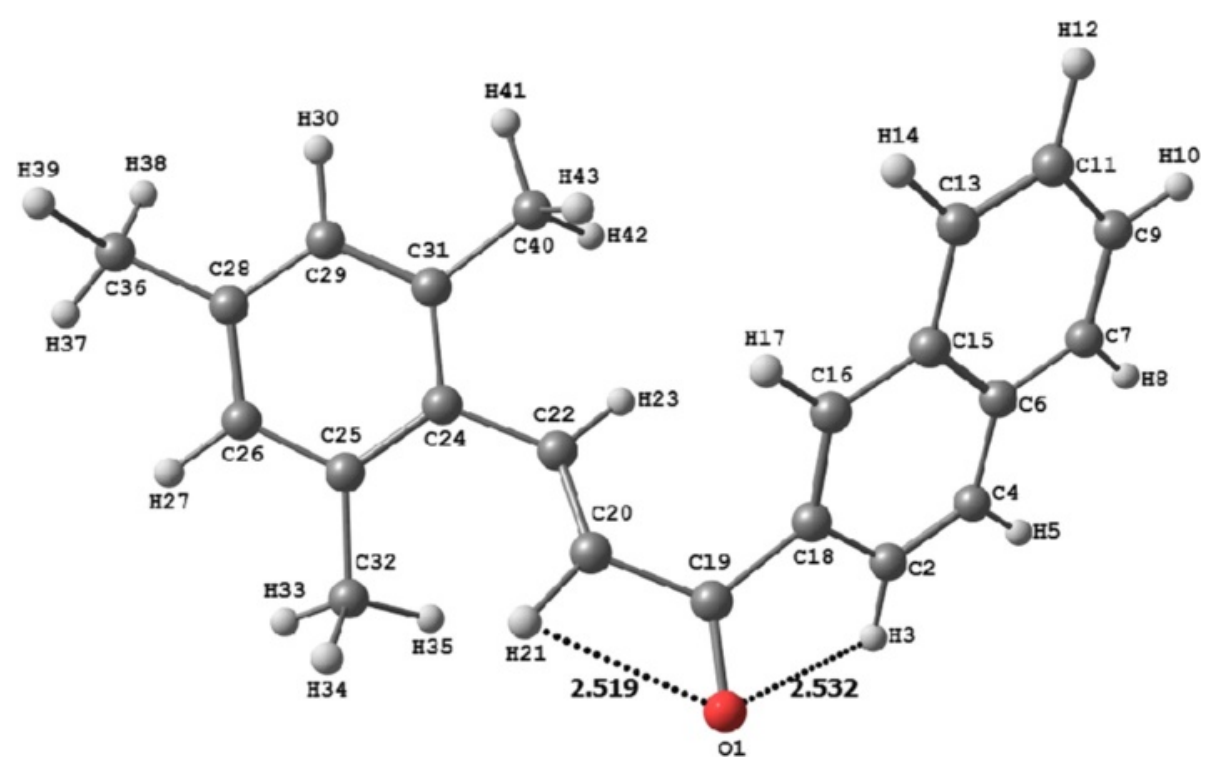

Fig. 3 The optimized molecular structure of 3

compound showed four electronic transition bands at 216, 258, 302 and $321 \mathrm{~nm}$. In agreement with the experimental data the calculations predicted these transition bands at $215.4 \mathrm{~nm}(\mathrm{f}=0.3187), 283.8 \mathrm{~nm}(\mathrm{f}=0.2028), 317.7 \mathrm{~nm}$ $(\mathrm{f}=0.2765)$ and $338.0 \mathrm{~nm}(\mathrm{f}=0.1023)$. The longest wavelength transition band is due to $\mathrm{H} \rightarrow \mathrm{L}$ (79 \%) excitation. The shortest wavelength band showed the highest intensity both experimentally and theoretically. The presence of some deviations between the calculated and the experimental data is attributed to the medium effect.

\section{Nonlinear optical properties}

Nonlinear optical materials were used as key materials for photonic communications which use light instead of electron for data transmission. With the development of laser technology, nonlinear optical materials have been extensively applied to industry, medicine and research $[36,37]$. Several organic materials were used for such applications. These organic compounds were characterized by their high polarizability $\left(\alpha_{0}\right)$ and low HOMOLUMO gap $(\Delta \mathrm{E})$. The $\alpha_{0}$ and $\Delta \mathrm{E}$ values of the studied compound are calculated to be $265.6 \mathrm{Bohr}^{3}$ and $4.2085 \mathrm{eV}$ respectively. The polarizability of the studied compound is about 10 times higher than urea.

The large value of the hyperpolarizability, $\beta$ is associated with intramolecular charge transfer resulting from an electron cloud movement through a $\pi$-conjugated framework. In this paper, the studied molecule was divided into two parts to evaluate the charge distribution, Part A for naphthalene ring and Part B is for the mesityl propenone moiety (Fig. 3). The total NAC value at part A is negative $(-0.0156)$. It is obvious that Part A serves as electron acceptor, while Part B is positively charged
$(+0.0156)$ and serve as electron donor. In the studied molecule, there is significant intramolecular charge transfer (ICT) from the naphthalene ring (part A) as electron donor to part B as electron acceptor. Such ICT is responsible for the high hyperpolarizability of the studied system.

Also the studied compound has lower energy gap $(\Delta \mathrm{E})$ compared to urea. Based on these calculations, the studied molecule is considered as better NLO material than urea which is used as reference molecule for comparison of the NLO activity [38].

\section{NMR spectra}

The isotropic magnetic shielding (IMS) values calculated using the GIAO approach at the 6-311G (d,p) level are used to predict the ${ }^{13} \mathrm{C}$ and ${ }^{1} \mathrm{H}$ chemical shifts $\left(\delta_{\text {calc }}\right)$ for the studied compound and the results are correlated to the experimental NMR data $\left(\delta_{\text {exp }}\right)$ in $\mathrm{CDCl}_{3}$ solvent. The experimental and theoretical values for ${ }^{1} \mathrm{H}$ - and ${ }^{13} \mathrm{C}$-NMR chemical shifts of the studied compound are given in Additional file 1: Table S3. According to these results, the calculated chemical shifts are in compliance with the experimental findings. As shown in Fig. 8, the agreement between the experimental and the calculated carbon-13 $\left(R^{2}=0.9965\right)$ and proton $\left(R^{2}=R^{2}=0.9911\right)$ chemical shifts are good.

\section{Analysis of the vibrational spectra}

The infrared vibrational frequencies and intensities of the titled compound were calculated using the DFT B3LYP/6-311G $(\mathrm{d}, \mathrm{p})$ method and the results are given in Additional file 1: Table S4. The experimental and predicted IR spectra of the studied compound are given in Fig. 9. Selected calculated and experimental vibrational 

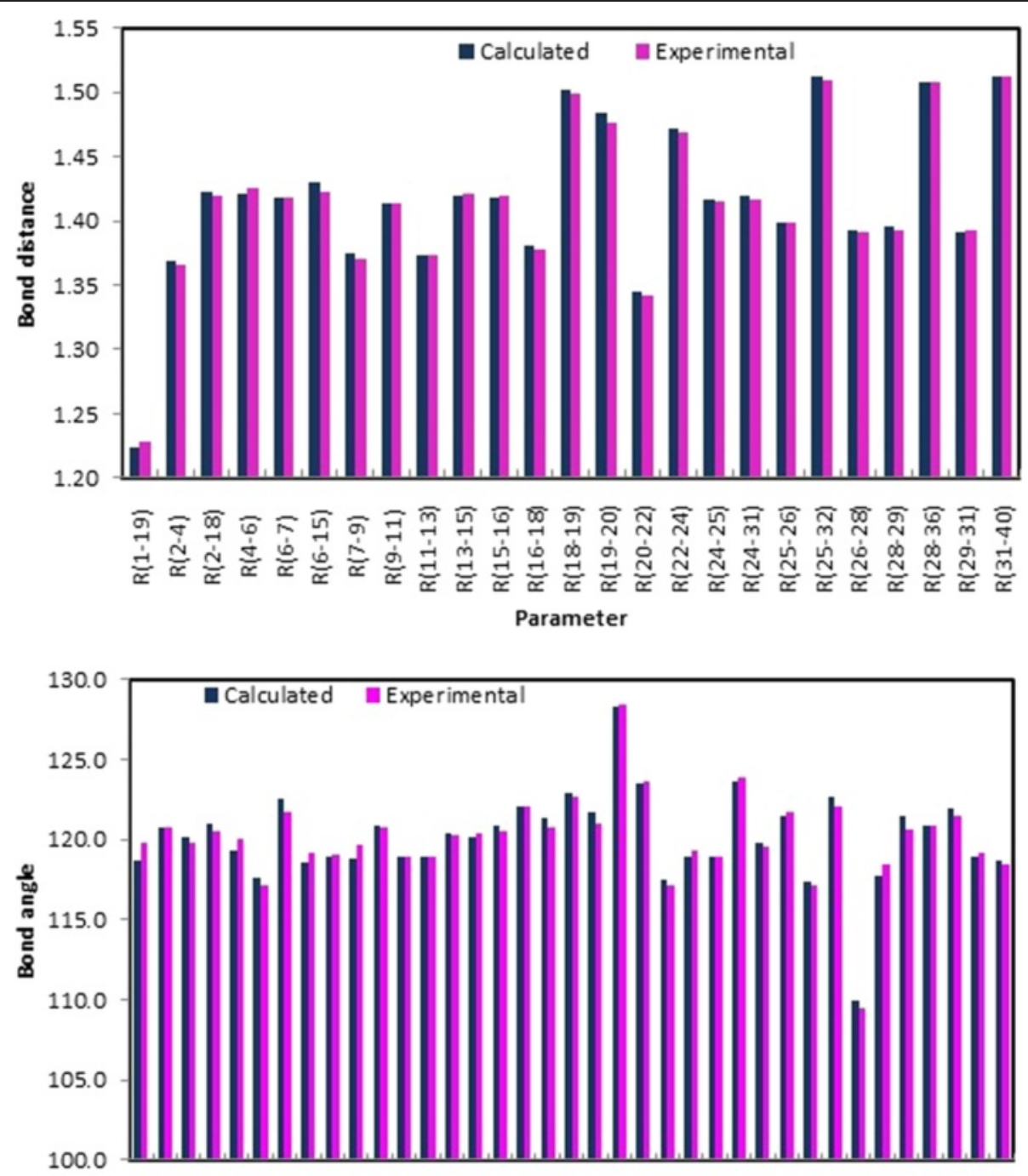

จิ

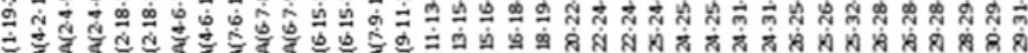

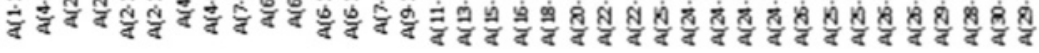

Parameter

Fig. 4 Comparison between the calculated and experimental geometric parameters (bond distances and bond angles) of 3

frequencies along with their assignments are presented in Table 5. A correlation graph between the calculated and the experimental vibrational frequencies is shown in Fig. 10. As can be seen from this figure, good correlation is obtained between the calculated and the experimental vibrational frequencies with high correlation coefficient $\left(\mathrm{R}^{2}=0.9996\right)$.

The studied compound has three types of $\mathrm{C}-\mathrm{H}$ bonds; 9 aromatic, 9 aliphatic and two vinylene groups. The aromatic stretching bands of the studied compound are calculated at 3096-3046 $\mathrm{cm}^{-1}$ (except $3092 \mathrm{~cm}^{-1}$ ) [39]. The seven $\mathrm{v}_{\mathrm{C}-\mathrm{H}}$ modes of the naphthalene ring are calculated at 3096, 3084, 3079, 3072, 3061, 3059 and $3055 \mathrm{~cm}^{-1}$ [39] while the two bands calculated at 3048 and $3046 \mathrm{~cm}^{-1}$ are assigned to the symmetric and asymmetric $\mathrm{C}-\mathrm{H}$ stretching vibration of the benzene ring, respectively. Both cis and trans dialkyl substituted ethylene $(\mathrm{RCH}=\mathrm{CHR})$ have a C-H stretches in the range 3020-2995 $\mathrm{cm}^{-1}$ [40]. The two $\mathrm{v}_{\mathrm{C}-\mathrm{H}}$ modes of the vinylene group are calculated at 3092 and $3053 \mathrm{~cm}^{-1}$. The high frequency values of these stretching modes probably due to the presence of nonalkane substituents attached to the vinylene group [40].

The aromatic ring $\mathrm{C}-\mathrm{H}$ in-plane bending vibrations are calculated at 1362-1333, 1265-1116 and $1008 \mathrm{~cm}^{-1}$ while the $\mathrm{C}-\mathrm{H}$ out-of-plane bending vibrations are calculated at 967, 960, 937, 904-816, 765 and 748-691 $\mathrm{cm}^{-1}$. The visual inspection of the vibrational modes showed that the $\mathrm{C}-\mathrm{H}$ in-plane bending vibrations of the vinylene 
Table 4 The natural atomic charges calculated at the B3LYP/6-311G (d,p) method

\begin{tabular}{|c|c|c|c|}
\hline Atom & NAC & Atom & NAC \\
\hline$\overline{\mathrm{O} 1}$ & -0.5524 & $\mathrm{H} 23$ & 0.2043 \\
\hline $\mathrm{C} 2$ & -0.1644 & $\mathrm{C} 24$ & -0.0997 \\
\hline $\mathrm{H} 3$ & 0.2212 & $\mathrm{C} 25$ & 0.0298 \\
\hline $\mathrm{C} 4$ & -0.1730 & $\mathrm{C} 26$ & -0.2169 \\
\hline $\mathrm{H} 5$ & 0.2032 & $\mathrm{H} 27$ & 0.1961 \\
\hline $\mathrm{C} 6$ & -0.0445 & $\mathrm{C} 28$ & 0.0140 \\
\hline $\mathrm{C7}$ & -0.1776 & $\mathrm{C} 29$ & -0.2200 \\
\hline $\mathrm{H} 8$ & 0.2024 & C30 & 0.1960 \\
\hline $\mathrm{CP}$ & -0.1886 & C31 & 0.0310 \\
\hline $\mathrm{H} 10$ & 0.2028 & $\mathrm{C} 32$ & -0.5901 \\
\hline $\mathrm{C} 11$ & -0.1976 & $\mathrm{H} 33$ & 0.2026 \\
\hline $\mathrm{H} 12$ & 0.2030 & $\mathrm{H} 34$ & 0.2084 \\
\hline $\mathrm{C} 13$ & -0.1710 & H35 & 0.2171 \\
\hline $\mathrm{H} 14$ & 0.2006 & C36 & -0.5829 \\
\hline $\mathrm{C} 15$ & -0.0579 & $\mathrm{H} 37$ & 0.2024 \\
\hline $\mathrm{C} 16$ & -0.1576 & $\mathrm{H} 38$ & 0.2055 \\
\hline $\mathrm{H} 17$ & 0.2087 & $\mathrm{H} 39$ & 0.2096 \\
\hline $\mathrm{C} 18$ & -0.1253 & $\mathrm{C} 40$ & -0.5897 \\
\hline C19 & 0.5286 & $\mathrm{H} 41$ & 0.2047 \\
\hline $\mathrm{C} 20$ & -0.2669 & $\mathrm{H} 42$ & 0.2083 \\
\hline $\mathrm{H} 21$ & 0.2114 & $\mathrm{H} 43$ & 0.2063 \\
\hline $\mathrm{C} 22$ & -0.1419 & & \\
\hline
\end{tabular}

group are calculated at 1318 and $1278 \mathrm{~cm}^{-1}$ (exp. 1299 and $1290 \mathrm{~cm}^{-1}$ ) while the out-of-plane bending modes are calculated at 995 and $883 \mathrm{~cm}^{-1}$ (exp. 996 and $885 \mathrm{~cm}^{-1}$ ).

According to Pulay et al. [41], the methyl $\left(\mathrm{CH}_{3}\right)$ group has five types of vibrational frequencies namely: symmetric stretch, asymmetric stretch, symmetric deformation, asymmetric deformation and rocking. The studied

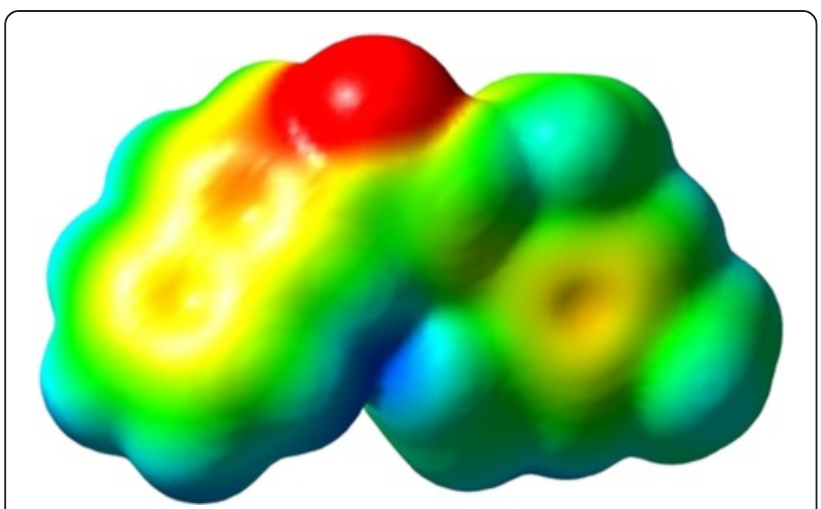

Fig. 5 Molecular electrostatic potentials (MEP) mapped on the electron density surface calculated by the DFT/B3LYP

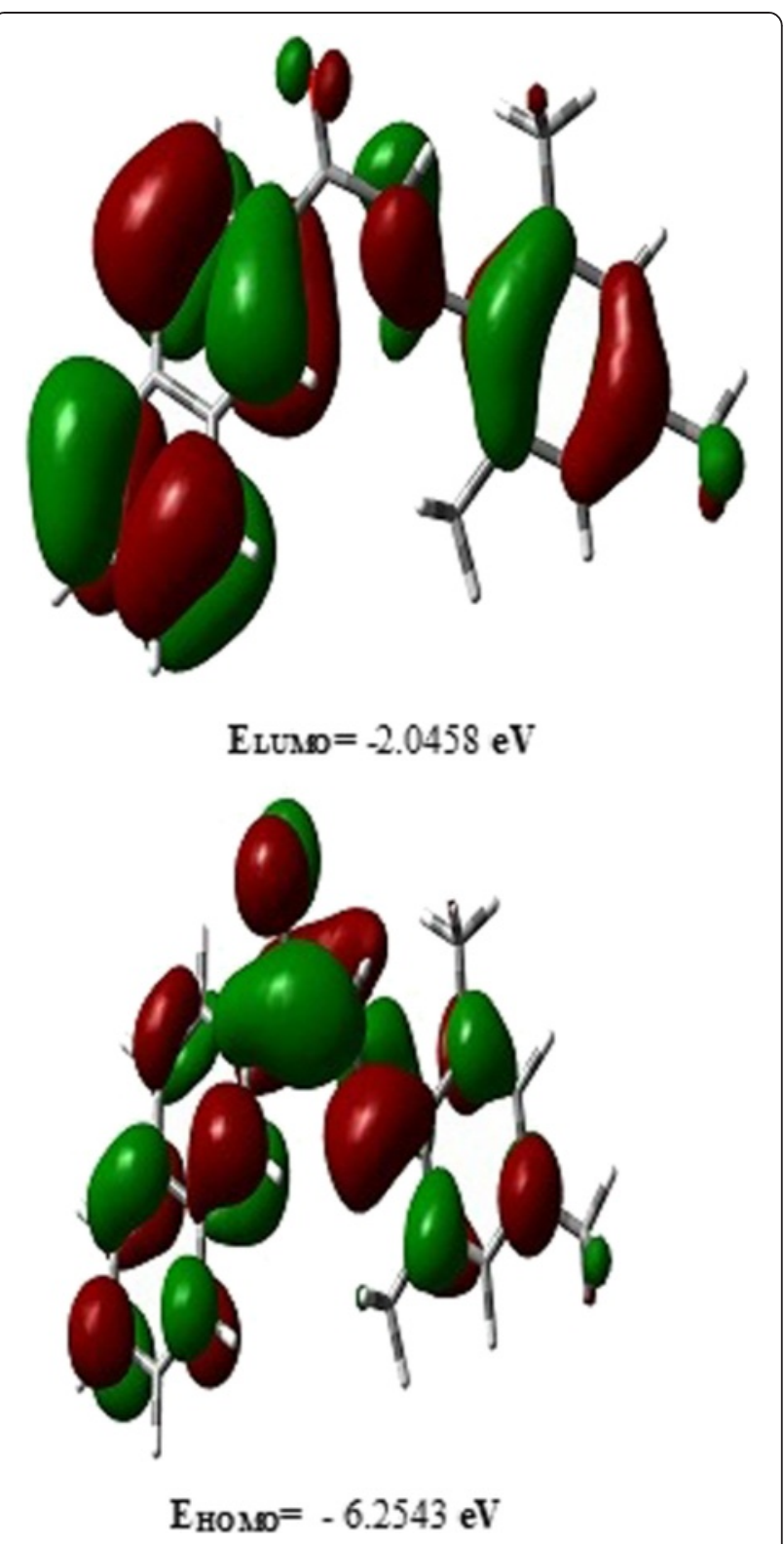

Fig. 6 The ground state isodensity surface plots for the frontier molecular orbitals

molecule has three methyl groups; the 9 stretching modes are calculated in the range $3011-2971 \mathrm{~cm}^{-1}$ (exp. 3016-2919 $\mathrm{cm}^{-1}$ ) and 2928-2922 (exp. $2852 \mathrm{~cm}^{-1}$ ) for the asymmetric and symmetric stretching vibrations respectively [42]. The asymmetric stretch is usually at higher frequency than the symmetric one. The asymmetric and symmetric bending vibrations of methyl groups are predicted in the region $1466-1441 \mathrm{~cm}^{-1}$ and 1419 $1396 \mathrm{~cm}^{-1}$, respectively [43,434]. The umbrella modes were calculated in the range $1373-1367 \mathrm{~cm}^{-1}$. The rocking vibrations of the $\mathrm{CH}_{3}$ group appear as mixed vibrations and usually appear in the region $1170-1100 \mathrm{~cm}^{-1}$ $[43,44]$. The $\mathrm{CH}_{3}$ rocking modes, which are coupled 

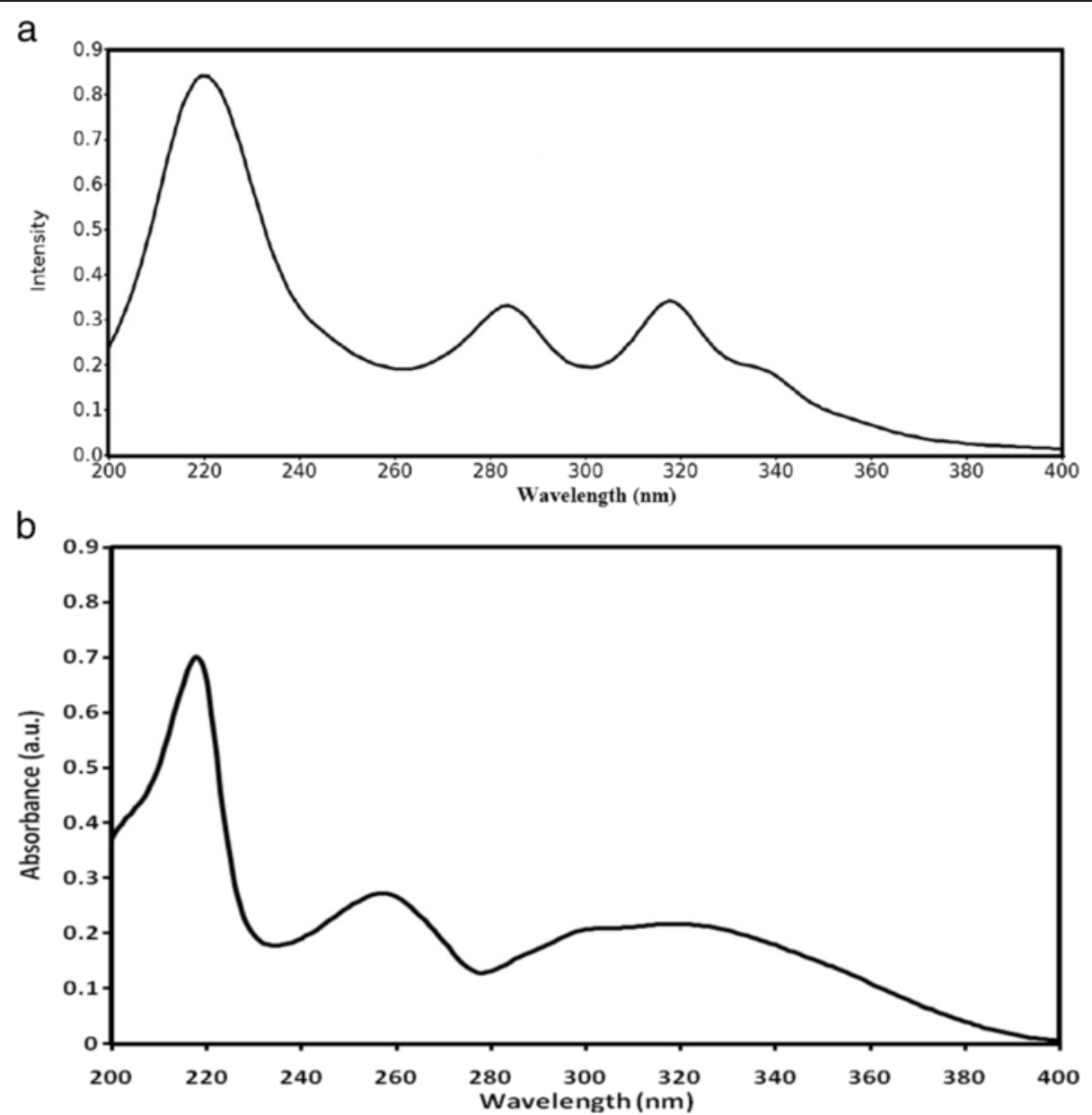

Fig. 7 The calculated (a) and experimental (b) electronic spectra of 3

with other vibration modes, are predicted in the frequency region of 1049-1014 $\mathrm{cm}^{-1}$ (exp. 1049-1014 $\mathrm{cm}^{-1}$ ). Moreover, the studied compound has one carbonyl group $(\mathrm{C}=\mathrm{O})$. The carbonyl stretching vibrations generally appear in the region $1750-1600 \mathrm{~cm}^{-1}$. In the present case, the absorption band observed at $1626 \mathrm{~cm}^{-1}$ (cal. $1649 \mathrm{~cm}^{-1}$ ) are assigned to the conjugated $\mathrm{C}=\mathrm{O}$ group. Also, the $\mathrm{v}_{\mathrm{C} 20=\mathrm{C} 22}$ and the aromatic ring $\mathrm{C}-\mathrm{C}$ vibrational frequencies are calculated at $1614 \mathrm{~cm}^{-1}$ (exp. $1604 \mathrm{~cm}^{-1}$ ) and $1611-1489 \mathrm{~cm}^{-1}$ (exp. $1546-1500 \mathrm{~cm}^{-1}$ ) respectively. These results are in agreement with the literature [45].

\section{Thermogravimetric Analysis (TGA)}

The TGA of the studied compound is performed over the temperature range $25-800{ }^{\circ} \mathrm{C}$ under flowing nitrogen atmosphere and the result is shown in Fig. 11. The TGA data showed that the studied compound is thermally stable up to $205{ }^{\circ} \mathrm{C}$ then undergo either sublimation or decomposition into volatile products in a fast step leaving almost $0 \%$ residue.

\section{Molecular docking simulation}

PASS (Prediction of Activity Spectra) is an online tool [46] which predicts almost 900 types of activities based on the structure of a compound. PASS analysis (Additional file 1: Table S5) of the title compound 3 predicts anti-diabetic activity (human histone acetyltransferase) with $\mathrm{Pa}$ (probability to be active) value of 0.348 . To evaluate the inhibitory nature of the title compound against human histone acetyltransferase, molecular docking simulations were carried out. Molecular docking is an efficient method to get an insight into ligand-receptor interactions. Molecular docking studies were performed using Molecular Operating Environment (MOE) software (www.chemcomp.com). The 3D crystal structure of human histone acetyltransferase was downloaded from Protein Data Bank (PDB ID: $4 \mathrm{PZS}$ ) [47]. Before docking experiment, the title compound 3 was prepared for docking by minimizing its energy at B3LYP functional and 6-311G (d,p) basis set using Gaussian 03 software. Partial charges were calculated by Gasteiger method. Most macromolecular crystal structures contain little or no hydrogen coordinate data due to 


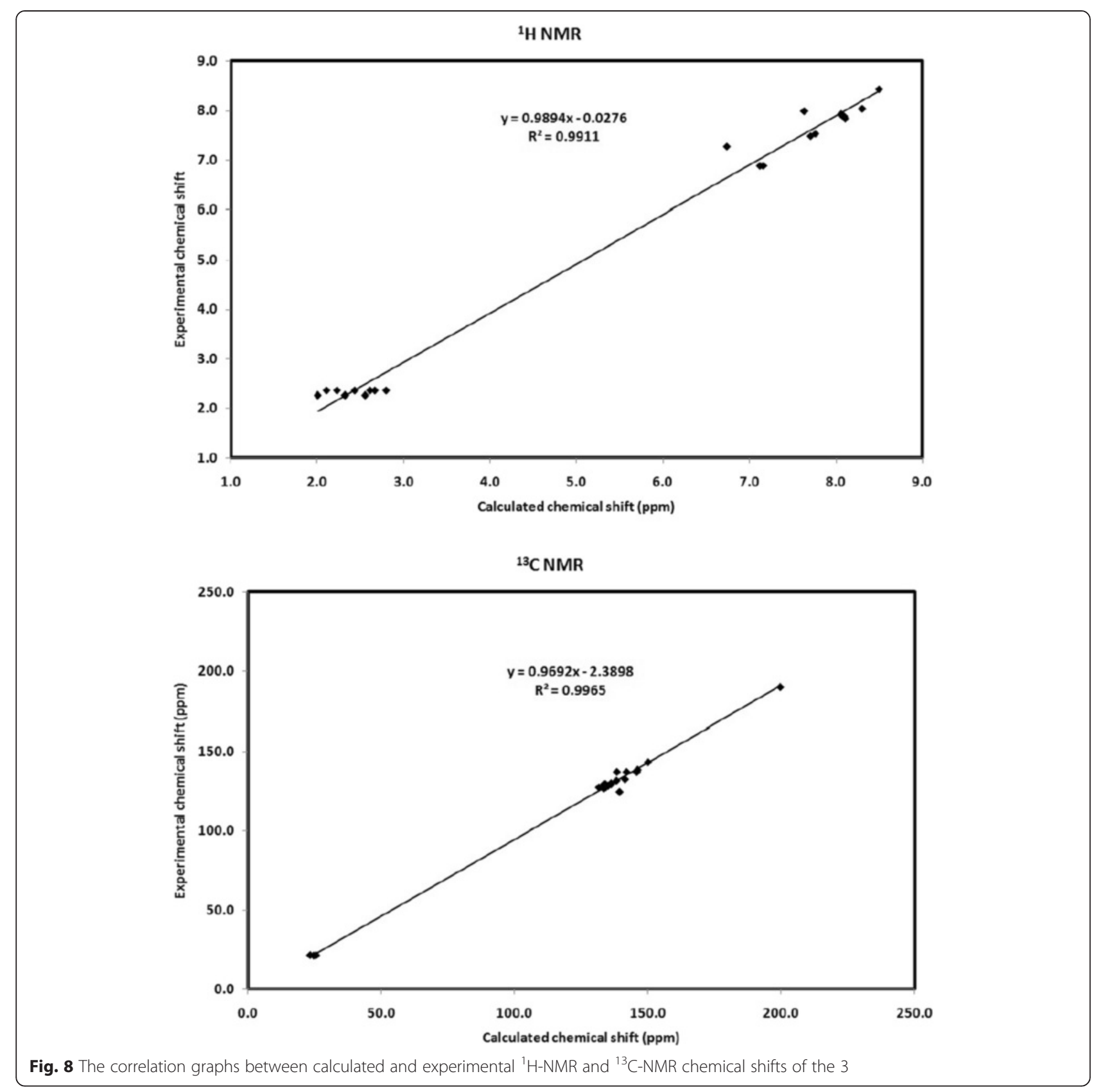

limited resolution and thus protonation was done prior to docking using Protonate 3D tools implemented in MOE. Protonation was followed by energy minimization up to 0.05 Gradient using Amber99 force field. The docking protocol predicted the same conformation as was present in the crystal structure with RMSD value close to the allowed range [48] and surrounded by the same active site residues of the enzyme. Amongst the generated docking conformations the top-ranked conformation was visualized for ligand-enzyme interaction using PyMol. Analysis of the docking results showed that the synthesized compound $\mathbf{3}$ fit well within the active site of histone acetyltransferase enzyme (Fig. 12a). From the docking conformation it was observed that both the naphthalene, mesitylene moiety as well as the carbonyl oxygen of 2-methylprop-1-ene moiety of the compound $\mathbf{3}$ interact with important active site residues of the enzyme, e.g., Arg124, Arg176 and Trp180. Arg176 was found in making two arene-cation interactions with both the phenyl ring of naphthalene moiety, Arg124 was involved in interaction with carbonyl oxygen of 2-methylprop-1-ene moiety and Trp180 was found in sharing its $\pi$-electron with the phenyl ring of the compound 3 and making $\pi-\pi$ interaction by which they stabilized the structure (Fig. 12b). 

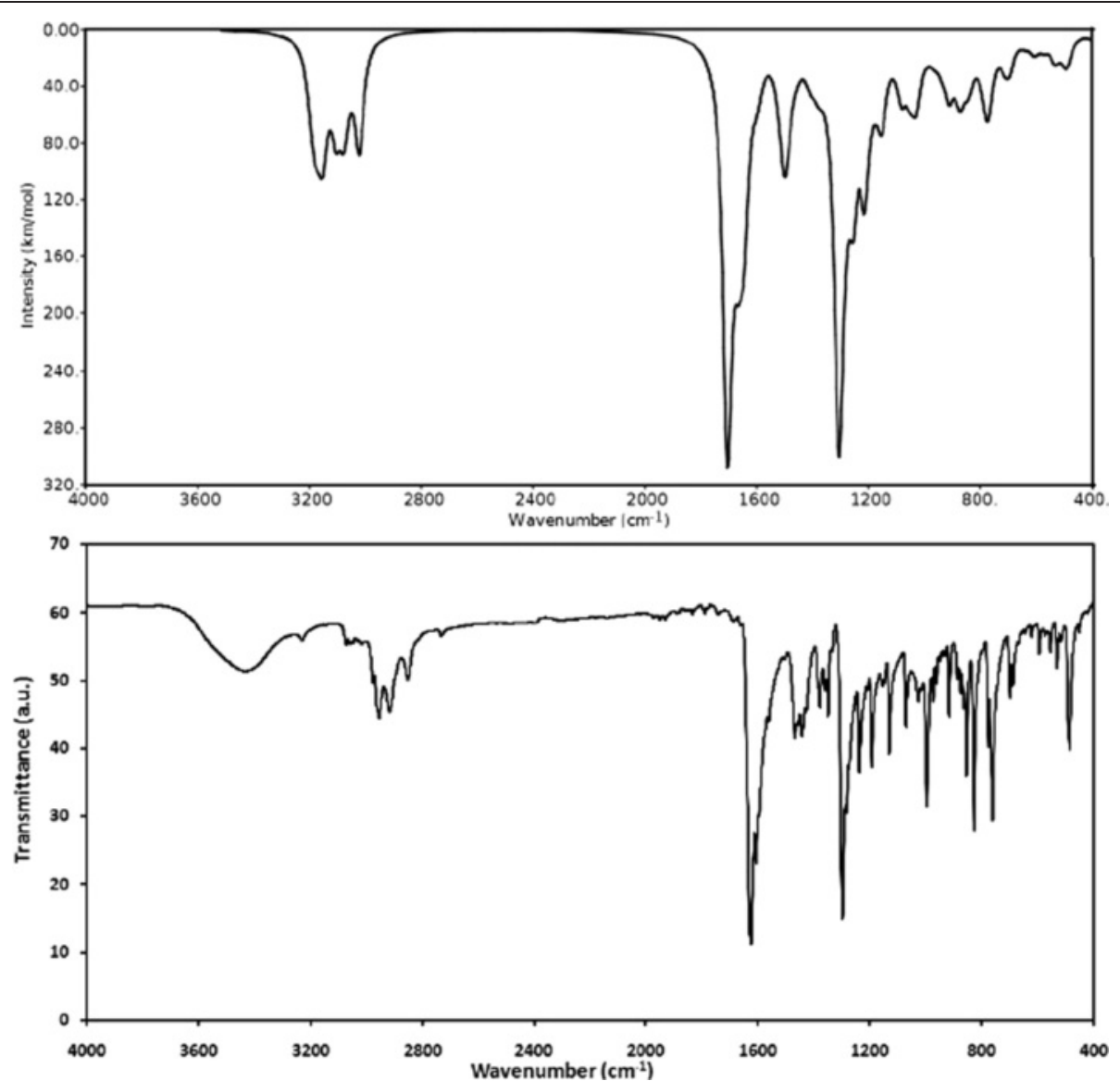

Fig. 9 The experimental (lower) and calculated (upper) infrared spectra of the 3

The presence of one $\mathrm{H}$-bond, one arene-arene and two arene-cation interactions confirm that the inhibitor may be specific to this site. These preliminary results suggest that the compound 3 might exhibit inhibitory activity against histone acetyltransferase enzyme and may act as potential anti-cancer compound. However, further biological tests should be done to validate the computational predictions.

\section{Experimental section}

\section{General}

All chemicals were purchased from Sigma-Aldrich, Fluka etc., and were used without further purification, unless otherwise stated. All melting points were measured on a Gallenkamp melting point apparatus in open glass capillaries and are uncorrected. IR Spectra were measured as $\mathrm{KBr}$ pellets on a Nicolet 6700 FT-IR spectrophotometer. The NMR spectra were recorded on a Varian Mercury Jeol-400 NMR spectrometer. ${ }^{1} \mathrm{H}-\mathrm{NMR}(400 \mathrm{MHz})$, and ${ }^{13} \mathrm{C}$-NMR $(100 \mathrm{MHz})$ were run in deuterated chloroform $\left(\mathrm{CDCl}_{3}\right)$. Chemical shifts $(\delta)$ are referred in terms of ppm and $J$-coupling constants are given in $\mathrm{Hz}$. Mass spectra were recorded on a Jeol JMS-600 H. Elemental analysis was carried out on Elmer 2400 Elemental Analyzer in $\mathrm{CHN}$ mode. The thermal analysis of the studied compound has been carried out using TGA Q500 V20.10. The wt\% loss was measured from ambient temperature to $800{ }^{\circ} \mathrm{C}$.

\section{X-ray crystallography}

Slow evaporation of ethanol solution of pure compound 3 yielded colorless crystals. A crystal of dimensions, $0.67 \times 0.27 \times 0.16 \mathrm{~mm}$ was selected for X-ray diffraction analysis. Data were collected on a Bruker APEX-II D8 Venture area diffractometer, equipped with graphite monochromatic Mo $\mathrm{K} \alpha$ radiation at $100{ }^{\circ} \mathrm{K}$. Cell refinement and data reduction were carried out by Bruker SAINT. SHELXS-97 $[49,50]$ was used to solve structure. The final refinement was carried out by full-matrix least-squares techniques with anisotropic thermal data for non-hydrogen atoms on $F^{2}$. All the hydrogen atoms were placed in calculated positions (Tables 1,2 and 3). The asymmetric unit of the crystal structure is shown in Fig. 1 and the crystal packing is shown in Fig. 2. 
Table 5 The calculated and experimental wavenumbers of the studied compound 3

\begin{tabular}{|c|c|c|}
\hline Assignment & Calculated & Experimental \\
\hline$U_{(\mathrm{CH}, \text { aromatic })}$ & $3096-3046$ & $3090-3030$ \\
\hline$U_{(=\mathrm{C} 2 \mathrm{OH} 21)}$ & 3092 & 3090 \\
\hline$U_{(=\mathrm{C} 22 \mathrm{H} 23)}$ & 3053 & \\
\hline $\mathrm{U}(\mathrm{CHasym}, \mathrm{CH} 3)$ & $3011-2971$ & $3016-2919$ \\
\hline$\left.U_{(\mathrm{CH} s y m,} \mathrm{CH} 3\right)$ & 2928-2922 & 2852 \\
\hline$U_{(C=O)}$ & 1649 & 1626 \\
\hline$U_{C 20}=C 22$ & 1614 & 1604 \\
\hline $\mathrm{U}_{\mathrm{C}=\mathrm{C}}$ (aromatic) & $1611-1489$ & $1546-1500$ \\
\hline$\delta_{C H}$ in-plane methyl & $1466-1441$ & $1469-1433$ \\
\hline$\delta_{\mathrm{CH}}$ out-of-plane methyl & 1419-1396 & 1391 \\
\hline$\delta_{\text {methyl umbrella }}$ & $1373-1367$ & 1365 \\
\hline$\delta_{\mathrm{CH}}$ aromatic in plane & $\begin{array}{l}\text { 1362-1333, 1265-1116, } \\
1008\end{array}$ & $1353,1345,1237-1130$ \\
\hline$\delta_{(=\mathrm{C}-\mathrm{H} \text { in plane })}$ & 1318,1278 & 1299,1290 \\
\hline$\delta_{\mathrm{CH}}$ aromatic out-of-plane & $\begin{array}{l}967,960,937,904-816, \\
765,748-691\end{array}$ & $\begin{array}{l}975,960,885-827,760, \\
745-680\end{array}$ \\
\hline$\delta_{(=C-H}$ out-of-plane) & 995,883 & 996,885 \\
\hline$\delta_{\text {methyl rocking }}$ & 1049-1014 & 1070-1015 \\
\hline
\end{tabular}

$u$ streching, $\delta$ bending

The structure of $\mathbf{3}$ was confirmed by X-ray crystal structure analysis (Bruker AXS GmbH). CCDC- 1026251 contains the supplementary crystallographic data for this compound. These data can be obtained free of charge from the Cambridge Crystallographic Data Centre via www.ccdc.cam.ac.uk/data_request/cif.
Preparation of (E)-3-mesityl-1-(naphthalen-2-yl) prop-2-en-1-one (3)

A mixture of 1-(naphthalen-2-yl) ethanone $1(1.5 \mathrm{mmol}$, $255.3 \mathrm{mg}), 2,4,6$-trimethylbenzaldehyde $2(1.5 \mathrm{mmol}$, $222.3 \mathrm{mg})$ in $10 \mathrm{~mL}$ EtOH. $\mathrm{NaOH}(2.0 \mathrm{mmol}, 80 \mathrm{mg})$ was dissolved in a mixture of EtOH: $\mathrm{H}_{2} \mathrm{O}(1: 1)$ in $10 \mathrm{~mL}$ and was added dropwise over $5 \mathrm{mins}$, the reaction mixture was stirred at room temperature for $24 \mathrm{~h}$ until TLC showed complete disappearance of the reactants. The product was precipitated and filtered off washed with $20 \mathrm{~mL}$ water, dried and recrystallized from $\mathrm{EtOH}$ to afford the pure product $3 . \mathrm{mp} .88^{\circ} \mathrm{C}$; IR $\left(v_{\max }\right)(\mathrm{KBr}) / \mathrm{cm}^{-1} 3441$, 2954, 2919, 2852, 1626, 1468, 1441, 1298; ${ }^{1} \mathrm{H}-\mathrm{NMR}$ $\left(400 \mathrm{MHz} ; \mathrm{CDCl}_{3}\right): \delta 2.26\left(\mathrm{~s}, 3 \mathrm{H}, \mathrm{CH}_{3}\right) ; 2.37(\mathrm{~s}, 6 \mathrm{H}$, $\left.2 \mathrm{xCH}_{3}\right) ; 6.89$ (s, 2H, Ph-H); $7.28(\mathrm{~d}, 1 \mathrm{H}, J=16.1 \mathrm{~Hz}, \mathrm{CH}=$ CHCO); 7.49 (td, $1 \mathrm{H}, J=8.0 \mathrm{~Hz} \& 1.5 \mathrm{~Hz}, \mathrm{Ar}-\mathrm{H}) ; 7.54(\mathrm{td}$, $1 \mathrm{H}, J=8.0 \mathrm{~Hz} \& 1.5 \mathrm{~Hz}$, Ar- $\mathrm{H}) ; 7.84(\mathrm{~d}, 1 \mathrm{H}, J=8.0 \mathrm{~Hz}$, $\operatorname{Ar}-\mathbf{H}) ; 7.89(\mathrm{~d}, 1 \mathrm{H}, J=8.8 \mathrm{~Hz}, \operatorname{Ar}-\mathrm{H}) ; 7.92(\mathrm{~d}, 1 \mathrm{H}, J=$ $8.1 \mathrm{~Hz}, \mathrm{Ar}-\mathrm{H}$ ); 7.99 (d, $1 \mathrm{H}, J=16.1 \mathrm{~Hz}, \mathrm{CH}=\mathrm{CHCO}), 8.05$ (dd, $1 \mathrm{H}, J=8.8 \mathrm{~Hz} \& 2.2 \mathrm{~Hz}, \mathrm{Ar}-\mathbf{H}) ; 8.43$ (s, $1 \mathrm{H}, \mathrm{Ar}-\mathbf{H})$; ${ }^{13} \mathrm{C}-\mathrm{NMR}\left(100 \mathrm{MHz} ; \mathrm{CDCl}_{3}\right)$ : 20.9, 21..2, 21.3, 124.5, 126.6, 127.6, 127.9, 128.2, 128.4, 129.2, 129.3, 129.4, 130.0, 131.6, 132.5, 135.5, 137.1, 138.5, 143.3, 190.3; MS m/z (\%):300.39 [M+, $98 \%$ ]; Anal. calcd. for $\mathrm{C}_{22} \mathrm{H}_{20} \mathrm{O}: \mathrm{C}, 87.96$; H, 6.71; Found: C, 87.99; H, 6.73.

\section{Conclusions}

The synthesis and characterization of (E)-3-mesityl-1(naphthalen-2-yl) prop-2-en-1-one 3 is reported. The TGA analysis showed high thermal stability of studied compound up to $205^{\circ} \mathrm{C}$. The molecular structure of the studied compound has been optimized using the DFT/

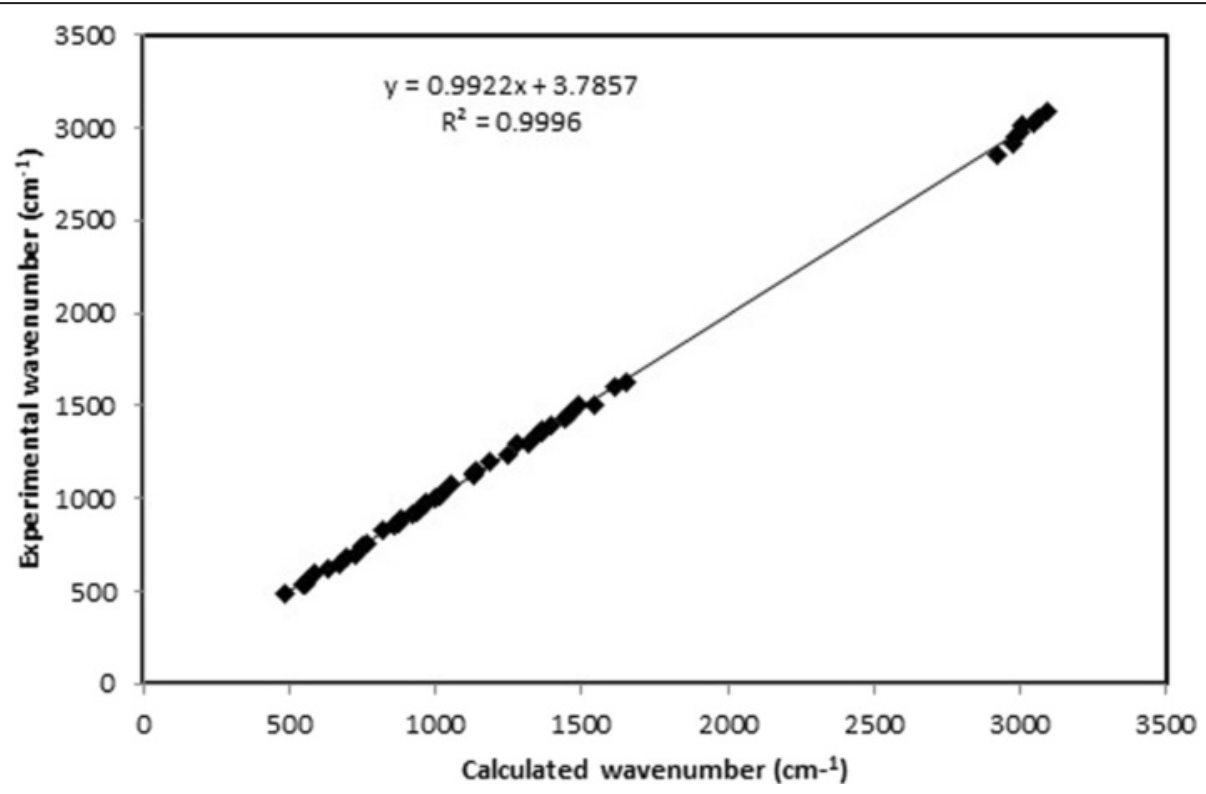

Fig. 10 Correlation graph between the calculated and experimental vibrational frequencies of the studied compound 


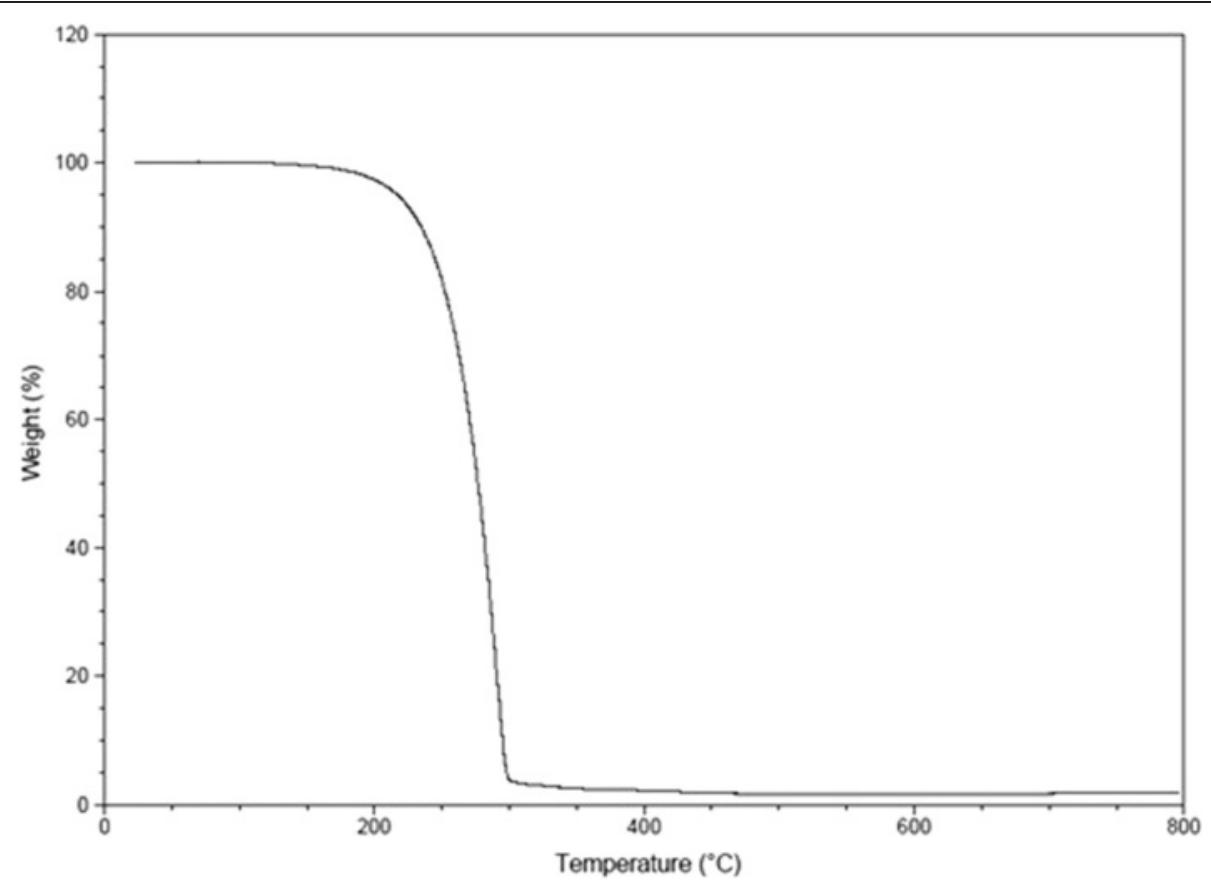

Fig. 11 The TGA curve of 3

B3LYP method and 6-311G (d,p) basis set. The calculated bond distances and bond angles showed good agreement with our reported X-ray crystal structure. The molecular electrostatic potential picture of the studied compound has been calculated using the same level of theory. The MEP results showed that the carbonyl oxygen (O5) is the most electronegative and the $\mathrm{H}$ atoms are the most electropositive sites. The $\alpha_{0}$ and HOMO-LUMO energy gap $(\Delta \mathrm{E})$ values indicated that the studied molecule is considered as a better NLO material than urea by 10 times. The calculated electronic spectra using the TD-DFT method showed four electronic transition bands at $215.4 \mathrm{~nm}(\mathrm{f}=0.3187)$, $283.8 \mathrm{~nm}(\mathrm{f}=0.2028), 317.7 \mathrm{~nm}(\mathrm{f}=0.2765)$ and $338.0 \mathrm{~nm}$ $(\mathrm{f}=0.1023)$. The GIAO ${ }^{1} \mathrm{H}$ - and ${ }^{13} \mathrm{C}-\mathrm{NMR}$ chemical shift values correlated well with the experimental data $\left(R^{2}=\right.$ 0.9911-0.9965). The IR vibrational frequencies are calculated and the fundamental bands were assigned and compared with the experimental data. Further studies towards the biological activity are in progress.

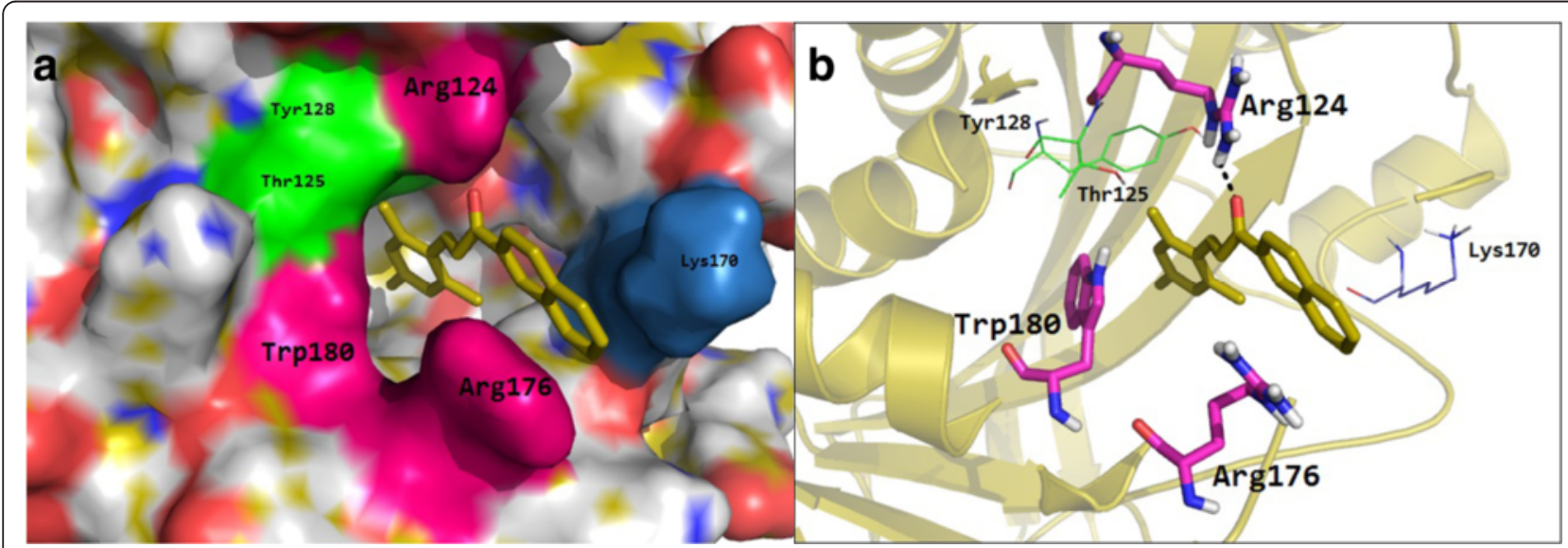

Fig. 12 a The title compound 3 was fit well in the cavity of histone acetyltransferase enzyme. $\mathbf{b}$ Docking conformation of title compound 3 (generated by MOE docking software) properly accommodated into the binding cavity of histone acetyltransferase enzyme and developed hydrogen bond and two arene-cation and arene-arene interactions with active site residue Arg176, Arg124 and Trp180. histone acetyltransferase 


\section{Additional file}

Additional file 1: Figure S1. ${ }^{1} \mathrm{H}-\mathrm{NMR}$ of the synthesized compound $\mathbf{3}$. Figure S2. ${ }^{13} \mathrm{C}-\mathrm{NMR}$ of the synthesized compound 3 . Table S1. Geometric parameters $\left(\AA,^{\circ}\right)$ compound 3. Table S2. The calculated electronic transitions using TD-DFT method. Table S3. The calculated chemical shifts $\delta$ (ppm) of the studied compound using GIAO method. Table S4. The calculated unscaled and scaled infrared vibrational frequencies of the studied compound. Table S5. PASS prediction of the compound, $\mathrm{Pa}$ represents probability to be active and Pi represents probability to be inactive.

\section{Competing interests}

The authors declare that they have no competing interests.

\section{Authors' contributions}

$A B$ proposed the subject, designed the study, helped in the results and discussion. MA carried out the synthesis of the studied compound. YNM and AMA conceived the study and participated in results, discussion, and coordination. HAG and HKF carried out X-ray part. SMS carried out the theoretical studies. AW carried out the molecular docking. AB prepared draft the manuscript. All the authors read and approved the final manuscript.

\section{Acknowledgements}

The authors would like to extend their sincere appreciation to the Deanship of Scientific Research at king Saud University for its funding this Research group NO (RG-257-1435-1436).

\section{Author details}

${ }^{1}$ Department of Chemistry, College of Science, King Saud University, P.O. Box 2455, 11451 Riyadh, Saudi Arabia. ${ }^{2}$ Department of Chemistry, Faculty of Science, Alexandria University, P.O. Box 426, 21321 Alexandria, Ibrahimia, Egypt. ${ }^{3}$ Department of Pharmaceutical Chemistry, College of Pharmacy King Saud University, P.O. Box 2457, 11451 Riyadh, Saudi Arabia. ${ }^{4}$ X-Ray Crystallography Unit, School of Physics, Universiti Sains Malaysia, 11800 USM Penang, Malaysia. ${ }^{5}$ Department of Biochemistry, Abdul Wali Khan University Mardan, 23200 Mardan, Pakistan.

Received: 29 November 2014 Accepted: 8 June 2015 Published online: 13 June 2015

\section{References}

1. Sortino M, Delgado P, Juarez S, Quiroga J, Abonia R, Insuasty B, et al. Synthesis and antifungal activity of (Z)-5-arylidenerhodanines. Bioorg Med Chem. 2007:15:484-94

2. Vargas MLY, Castelli MV, Kouznetsov W, Urbina GJM, Lopez SN, Sortino M, et al. In vitro antifungal activity of new series of homoallylamines and related compounds with inhibitory properties of the synthesis of fungal cell wall polymers. Bioorg Med Chem. 2003;11:1531-50.

3. Lopez SN, Castelli MV, Zacchino SA, Dominguez JN, Lobo G, Charris-Charris J, et al. In vitro antifungal evaluation and structure-activity relationships of a new series of chalcone derivatives and synthetic analogues, with inhibitory properties against polymers of the fungal cell wall. Bioorg Med Chem. 2001:8:1999-2013.

4. Avila HP, Smania EF, Monache FD, Smania A. Structure-activity relationship of antibacterial chalcones. Bioorg Med Chem. 2008;16:9790-4.

5. Katsori AM, Hadjipavlou-Litina D. Chalcones in cancer: understanding their role in terms of QSAR. Curr Med Chem. 2009;16:1062-82.

6. Achanta G, Modzelewska A, Feng L, Khan SR, Huan P. A boronic-chalcone derivative exhibits potent anticancer activity through inhibition of the proteasome. Mol Pharmacol. 2006;70:426-33.

7. Modzelewska A, Pettit C, Achanta G, Davidson NE, Huang P, Khan SR. Anticancer activities of novel chalcone and bis-chalcone derivatives. Bioorg Med Chem. 2006;14:3491-5.

8. Kumar SK, Hager E, Pettit C, Gurulingappa H, Davidson NE, Khan SR. Design, synthesis, and evaluation of novel boronic-chalcone derivatives as antitumor agents. J Med Chem. 2003:46:2813-5.

9. Cheng JH, Hung CF, Yang SC, Wang JP, Won SJ, Lin CN. Synthesis and cytotoxic, anti-inflammatory, and anti-oxidant activities of 2',5'-dialkoxylchalcones as cancer chemopreventive agents. Bioorg Med Chem. 2008;16:7270-6.
10. Xuelin $Y$, Wei W, Jun $T$, Dandan S, Ming L, Dan L, et al. Synthesis of a series of novel dihydroartemisinin derivatives containing a substituted chalcone with greater cytotoxic effects in leukemia cells. Bioorg Med Chem Lett. 2009;19:4385-8.

11. Marek TK, Wojciech K, Micha S, Andrzej S, Roland Wakiec EA, Zofia Z. Acid-catalyzed synthesis of oxathiolone fused chalcones. comparison of their activity toward various microorganisms and human cancer cells line. Eur J Med Chem. 2007;42:729-33.

12. Zohreh N, Saeed E, Samaneh H, Sussan KA, Maryam N, Fatemeh P, et al. Novel antileishmanialchalconoids: synthesis and biological activity of 1- or 3-(6-Chloro-2H-chromen-3-yl) propen-1-ones. Eur J Med Chem. 2010:45:1424-429.

13. Anastasia D, Maya M, Christos AK, Dimitra H, Panagiotis K. Natural and synthetic 2'-hydroxy-chalcones and aurones: synthesis, characterization and evaluation of the antioxidant and soybean lipoxygenase inhibitory activity. Bioorg Med Chem. 2009;17:8073-85.

14. Julio MA, Sylvia P, Diaz C, Josefina S, Francisco DV, Rivero IA. Solution-phase parallel synthesis of substituted chalcones and their antiparasitary activity against Giardia lamblia. Bioorg Med Chem. 2009;17:6780-5.

15. Anindra S, Bandana C, Munna PG, Jawed AS, Rituraj K, Rama PT. Synthesis and anti breast cancer activity of biphenyl based chalcones. Bioorg Med Chem. 2010;18:4711-20.

16. Mahrwald R. Modern aldol reactions, Vol. 1: enolates, organocatalysis, biocatalysis and natural product synthesis. Weinheim: WILEY-VCH Verlag GmbH \& Co. KGaA; 2004

17. Alberti KG, Zimmet PZ. Definition, diagnosis and classification of diabetes mellitus and its complications. Part 1: diagnosis and classification of diabetes mellitus provisional report of a WHO consultation. Diabet Med. 1998;15(7):539-53.

18. Alyar $\mathrm{H}$. A review on nonlinear optical properites of donon-accpetor derivatives of naphthalene and azanaphthalene. Rev Adv Mater Sci. 2013;34:79-87.

19. Prasad PN, Williams DJ. Introduction to nonlinear optical effects in molecules and polymers. New York: JohnWiley \& Sons; 1991.

20. Nalwa HS, Miyata S. Nonlinear optics of organic molecules and polymers, ed. Boca Raton, Florida: CRC Press; 1997.

21. Marder SR, Kippelen B, Jen AKY, Peyghambarian N. Design and synthesis of chromophores and polymers for electro-optic and photorefractive applications. Nature. 1997;388:845-51.

22. Shi Y, Zhang C, Bechtel JH, Dalton LR, Robinson BH, Steier WH. Low (sub-1-volt) halfwave voltage polymeric electro-optic modulators achieved by controlling chromophore shape. Science. 2000;288:119-22.

23. Kajzar F, Lee KS, Jen AKY. Polymeric materials and their orientation techniques for second-order nonlinear optics. Adv Polym Sci. 2003;161:1-85.

24. Krishnakumar V, Nagalakshmi R. Studies on the first-order hyperpolarizability and terahertz generation in 3-nitroaniline. Phys B. 2008:403:1863.

25. Barakat A, Al Majid AMA, Islam MS, Al-Othman ZA. Highly enantioselective friedel - crafts alkylations of indoles with a, $\beta$-unsaturated ketones under $\mathrm{Cu}$ (II)-simple oxazoline-imidazoline catalysts. Tetrahedron. 2013;69:5185-92.

26. Frisch MJ, Trucks GW, Schlegel HB, Scuseria GE, Robb MA, Cheeseman JR, et al. Gaussian-03, revision C.01. Wallingford, CT: Gaussian, Inc; 2004.

27. Dennington II R, Keith T, Millam J. GaussView, version 4.1. Shawnee Mission, KS: Semichem Inc; 2007.

28. Zhurko GA, Zhurko DA, Chemcraft. Lite version build 08 (Freeware: http://www.chemcraftprog.com/). 2005.

29. Glendening ED, Reed AE, Carpenter JE, Weinhold F. NBO version 3.1. Madison: Cl, University of Wisconsin; 1998.

30. Sidir I, Sidir YG, Kumalar M, Tasal E. Ab Initio Hartree-fock and density functional theory investigations on the conformational stability, molecular structure and vibrational spectra of 7-acetoxy-6-(2,3-dibromopropyl)-4,8dimethylcoumarin molecule. J Mol Struct. 2010;964:134-51.

31. Murray JS, Sen K. Molecular electrostatic potentials, concepts and applications. Amsterdam: Elsevier; 1996.

32. Scrocco E, Tomasi J. Electronic molecular structure, reactivity and intermolecular forces: an euristic interpretation by means of electrostatic molecular potentials. Adv Quantum Chem. 1978;11:115.

33. Fukui $\mathrm{K}$, Yonezawa $\mathrm{T}$, Shingu HJ. A molecular-orbital theory of reactivity in aromatic hydrocarbons. J Chem Phys. 1952;20:722-5.

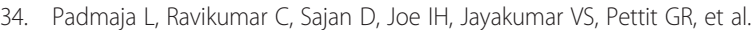
Density functional study on the structural conformations and intramolecular charge transfer from the vibrational spectra of the anticancer drug combretastatin-A2. J Raman Spectrosc. 2009;40:419-28. 


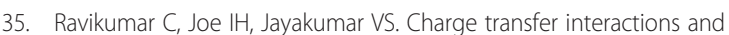
nonlinear optical properties of push-pull chromophore benzaldehyde phenyl hydrazone: a vibrational approach. Chem Phys Lett. 2008;460:552-8.

36. Gnanasekaran P, Madhavan J. Synthesis, structural, FT-IR and non-linear optical studies of pure and lanthanum doped l-arginine acetate single crystals. Asian J Chem. 2010;22:109-14.

37. Geskin VM, Lambert C, Bredas JL. Origin of high second- and third-order nonlinear optical response in ammonio/borato diphenylpolyene zwitterions: the remarkable role of polarized aromatic groups. J Am Chem Soc. 2003;125:15651-8

38. Pu LS. In materials for nonlinear optics, chemical perspectives. ACS Symp Ser. 1991:455:331-42.

39. Bellamy LJ. The infrared spectra of complex molecules. New York: John Wiley and Sons Inc:; 1975.

40. Clothup NB, Daly LH, Wiberley SE. Introduction to infrared and Raman spectroscopy. 3rd ed. San Diego, CA: Chapter 9, Academic Press; 1990. p. 310-2.

41. Pulay P, Fogarasi G, Pang F, Boggs JE. Systematic ab initio gradient calculation of molecular geometries, force constants, and dipole moment derivatives. J Am Chem Soc. 1979;101:2550-60.

42. Silverstein RM, Basseler GC, Morill C. Spectroscopic identification of organic compounds. New York: Wiley; 1981.

43. Smith B. Infrared spectral interpretation, a systematic approach. Washington, DC: CRC Press; 1999

44. Dollish FR, Fateley WG, Bentley FF. Characteristic Raman frequencies of organic compounds. New York: John Wiley \& Sons; 1997.

45. Silverstein RM, Webster FX, Kiemle DJ. Spectrometric identification of organic compounds. 7th ed. New York: John Wiley \& Sons; 2005.

46. Lagunin A, Stepanchikova A, Filimonov D, Prorikov V. PASS: prediction of activity spectra for biologically active substances. Bioinformatics. 2000;16:747-8.

47. Oikonomakos NG, Skamnaki VT, Tsitsanou KE, Gavalas NG, Johnson LN A new allosteric site in glycogen phosphorylase $b$ as a target for drug interactions. Structure. 2000;15:575-84.

48. Paul MK, Mukhopadhyay AK. Tyrosine kinase - role and significance in cancer. Int J Med Sci. 2004;1:101-15.

49. Sheldrick GM. A short history of SHELX. Acta Cryst. 2008:A64:112-22.

50. Spek AL. Structure validation in chemical crystallography. Acta Cryst. 2009:D65:148-55. 